\title{
THE EFFECTS OF ELECTRODE MOVEMENTS ON SMAW WELDING TO THE QUALITY OF ST-37 STEEL WELDS
}

\author{
Nur Akhmad Triwibowo"), Eka Supriatna ${ }^{2)}$ \\ Program Studi Teknik Mesin Sekolah Tinggi Teknologi Adisutjipto \\ Jalan Janti Blok R Lanud Adisutjipto Yogyakarta \\ Email : ${ }^{1}$ akhmadtriwibowo@gmail.com
}

\begin{abstract}
Many factors affect the welding results including electrode movement, welding current and electrode type. This study aims to determine the effects of electrode movements on SMAW welding to the quality of ST-37 steel welds. The quality reviewed includes microstructure, tensile strength, yield strength and weld defects. The study used ST 37 Steel with thickness $10 \mathrm{~mm}$ and a size of $100 \mathrm{~mm} \times 200 \mathrm{~mm}$, open V seam with an angle of $60^{\circ}$ degree. E 7016 series electrodes had a diameter of $3.2 \mathrm{~mm}$. Welding current $90-92$ amperes, polarity $D C+$, welding voltage 25 volts and travel speed $8-10 \mathrm{~cm} /$ minute. Electrode movements variations include straight, zig-zag and spiral movement. The results showed that the micro structure of the Acicular Ferrite $(A F)$ on the electrode spiral movement looks uniform, tight, dominates the area. Furthermore the spiral movement of the electrode provides the highest tensile strength, provides the highest yield strength and does not produce welding defects.
\end{abstract}

Keywords: electrode movements, SMAW, welds quality, ST-37 Steel.

\section{Pendahuluan}

Teknik pengelasan telah digunakan secara umum dalam penyambungan logam pada konstruksi bangunan baja dan konstruksi mesin. Jenis pengelasan yang sering digunakan adalah pengelasan SMAW (Shielded Metal arc Welding)[1]. Teknik pengelasan logam merupakan salah satu proses manufaktur yang banyak digunakan di berbagai industri seperti otomotif, perpipaan, perkapalan, jembatan, bangunan lepas pantai dan bahkan dewasa ini sudah digunakan untuk menyambung panel-panel pada bodi pesawat terbang (fuselage).

Faktor yang mempengaruhi las adalah prosedur pengelasan yaitu suatu perencanaan yang meliputi cara pembuatan kontruksi las yang sesuai rencana dan spesifikasi dengan menentukan semua hal yang diperlukan dalam pelaksanaan tersebut. Faktor produksi pengelasan adalah jadwal pembuatan, proses pembuatan, alat dan bahan yang diperlukan, urutan pelaksanaan, persiapan pengelasan meliputi: pemilihan mesin las, penunjukan juru las, pemilihan elektroda dan penggunaan jenis kampuh[2].

Banyak faktor yang mempengaruhi hasil pengelasan antara lain gerakan elektroda, arus pengelasan dan tipe elektroda[3]. Gerakan elektroda atau ayunan elektroda dapat mempengaruhi kualitas lasan karena gerakan elektroda dilakukan untuk menghasilkan rigirigi las yang baik dan memperdalam penembusan busur nyala.

Beberapa studi telah meneliti pengaruh gerakan elektroda pada hasil lasan. Teknik pengelasan alur spiral, zig-zag, dan lurus arus 85 A berpengaruh tetapi tidak signifikan pada kekuatan tarik baja ST 41 pada las listrik SMAW[2]. Kombinasi variabel uji kekuatan tarik paling tinggi adalah gerakan elektroda spiral sebesar $33.40 \mathrm{kgf} / \mathrm{mm}^{2}$, sedangkan hasil yang paling rendah gerakan elektroda lurus sebesar $30.28 \mathrm{kgf} / \mathrm{mm}^{2}$ [3]. Selain itu, pengelasan baja karbon rendah agar mendapatkan nilai kekuatan bending yang tinggi adalah menggunakan gerakan segitiga dengan nilai sebesar 523,05 N/mm²[4]. 
Penelitian mengenai pengaruh gerak elektroda pada kualitas hasil lasan telah banyak dilakukan. Meskipun demikian, penelitian mengenai pengaruh gerak elektroda pada pengelasan SMAW terhadap kualitas hasil lasan plat baja ST 37 belum terdokumentasi dengan baik. Penelitian ini bertujuan untuk mengetahui pengaruh gerak elektroda pada pengelasan SMAW terhadap kualitas hasil lasan plat baja ST 37. Kualitas yang ditinjau meliputi struktur mikro, kekuatan tarik, tegangan luluh dan cacat las.

\section{Metodologi Penelitian}

\subsection{Proses Pengelasan}

Baja ST 37 dengan tebal $10 \mathrm{~mm}$ dipotong dengan ukuran $100 \mathrm{~mm}$ x $200 \mathrm{~mm}$. Pada sisinya dibuat kampuh V terbuka dengan kemiringan sudut $60^{\circ}$ (Gambar 1) Plat baja disusun berpasangan dan dilakukan pengelasan SMAW pada sisinya (Gambar 1). Elektroda yang digunakan seri E 7016 dengan diameter 3,2 mm. Arus pengelasan 90-92 ampere polaritas $\mathrm{DC}+$, tegangan pengelasan 25 volt dan travel speed $8-10 \mathrm{~cm} / \mathrm{menit}$. Variasi gerak elektroda pada pengelasan SMAW meliputi gerak lurus, zig-zag (Gambar 2) dan spiral (Gambar 3). Pengelasan dilakukan di Inlastek Solo.
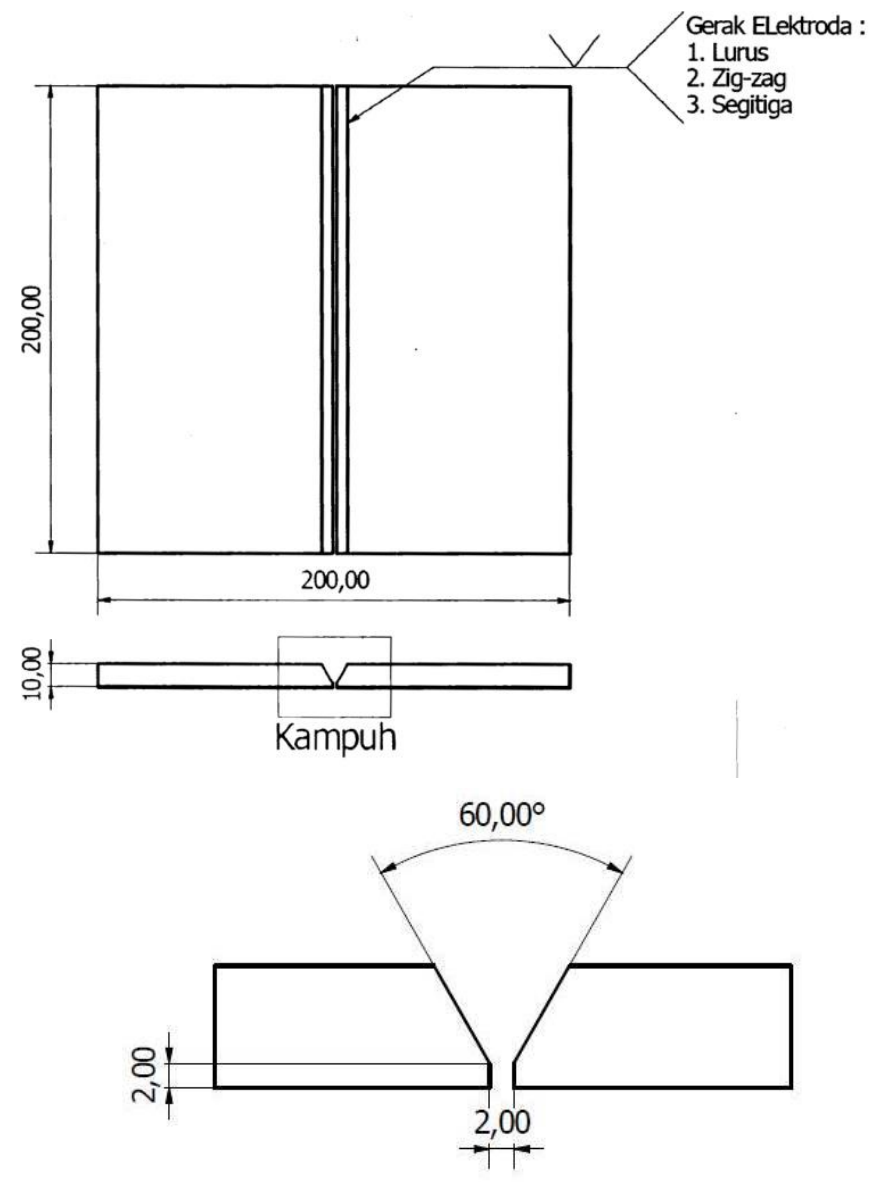

Gambar 1. Dimensi Pengelasan dan Kampuh V Plat Baja ST 37 


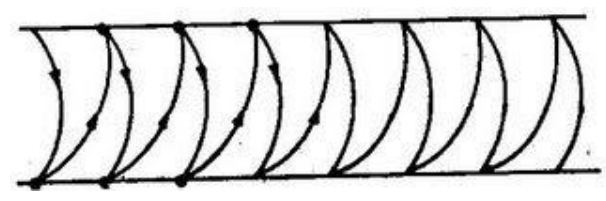

Gambar 2. Gerak Zig-zag Elektroda

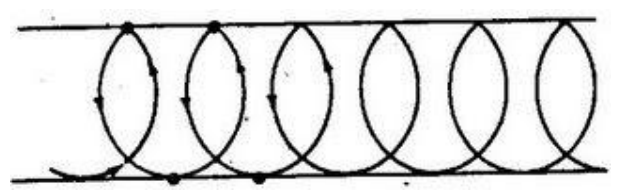

Gambar 3. Gerak Spiral Elektroda

\subsection{Proses Pengujian.}

Untuk mengetahui kualitas hasil lasan dilakukan pengujian tarik dan analisa astruktur mikro. Pengujian tarik menggunakan metode ASTM E8/E8M dengan dimensi specimen seperti pada Gambar 4. Analisa struktur mikro mempergunakan mikroskop dengan perbesaran 200 kali.

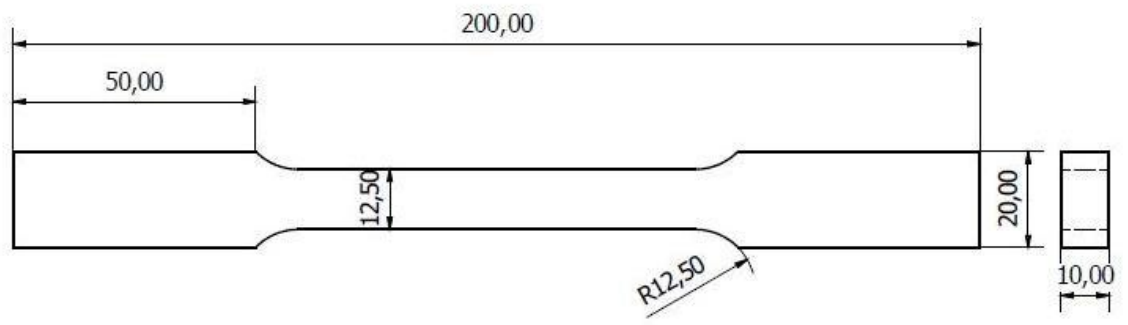

Gambar 4. Dimensi Specimen Uji Tarik Dengan Metode ASTM E8 / E8M

\section{Hasil dan Pembahasan}

\subsection{Struktur Mikro}

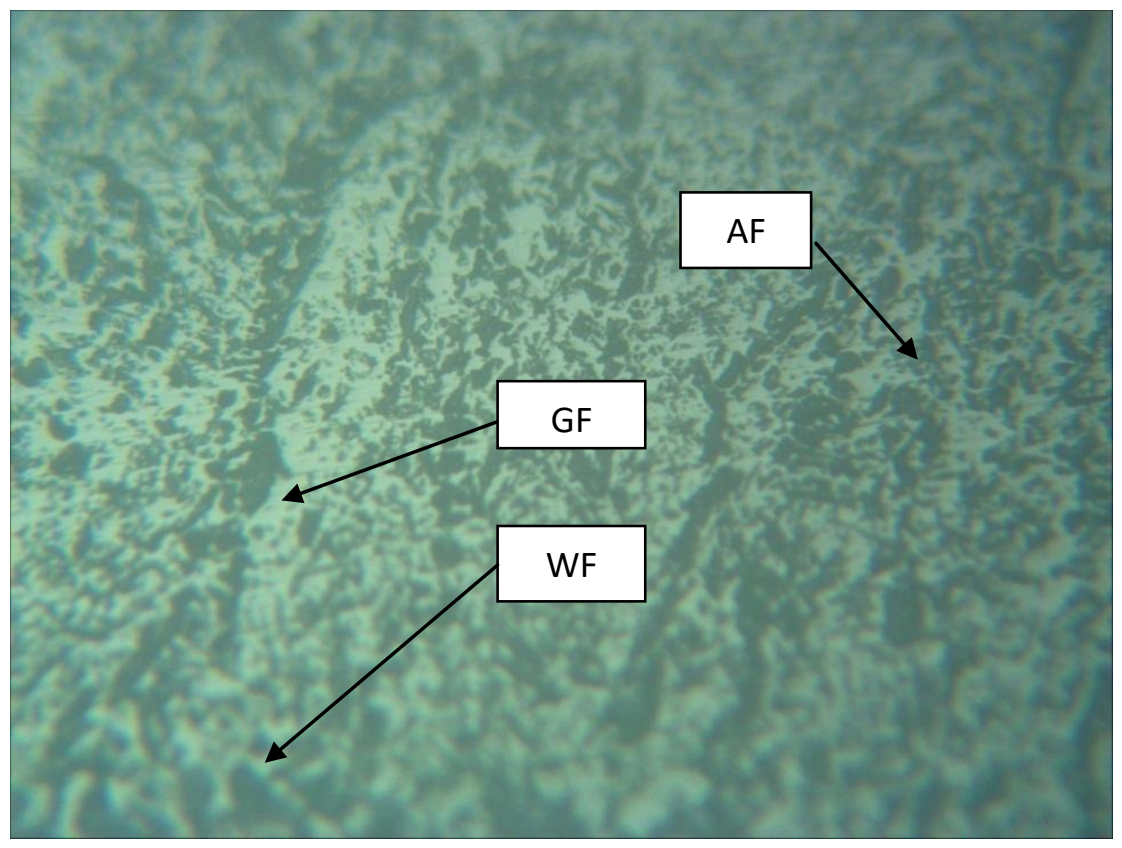

Gambar 5. Struktur Mikro Lasan Dengan Gerak Lurus Elektroda 
Struktur mikro lasan dengan gerak lurus elektroda (Gambar 5) terlihat struktur mikro lasan yang terdiri dari Grain Boundary Ferrite (GF), Widmanstatten Ferrite (WF) dan Acicular Ferrite (AF). Struktur mikro GF dan AF terlihat merata hampir di seluruh bagian. Namun demikian struktur mikro WF terlihat hanya di beberapa bagian.

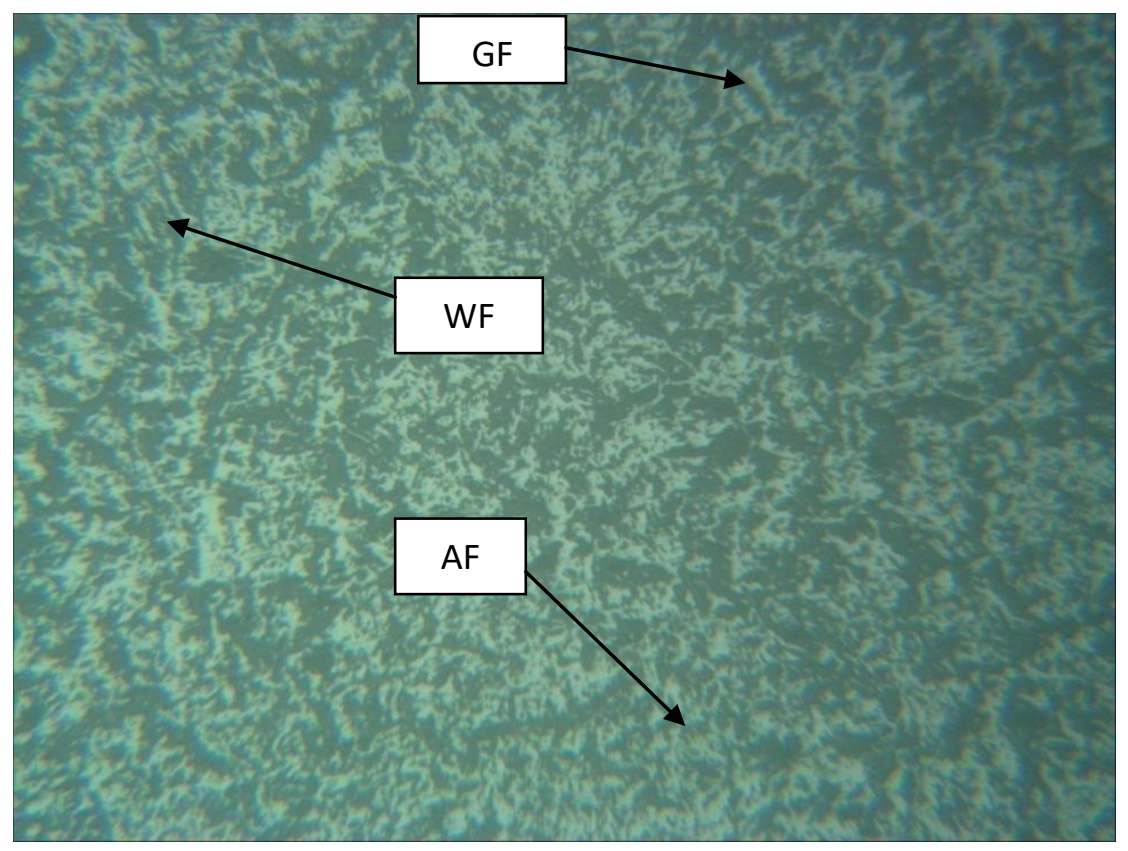

Gambar 6. Struktur Mikro Lasan Dengan Gerak Zig-zag Elektroda

Struktur mikro lasan dengan gerak zig-zag elektroda (Gambar 6) terlihat struktur mikro Grain Boundary Ferrite (GF), Widmanstatten Ferrite (WF) dan Acicular Ferrite $(A F)$. Struktur mikro WF terlihat hanya sedikit di bagian kecil dari area tersebut. Struktur mikro AF terlihat berbutir lembut dan mendominasi area, sedangkan struktur mikro GF terlihat kecil dan lebih sedikit dibanding GF yang ada pada Gambar 5. . 


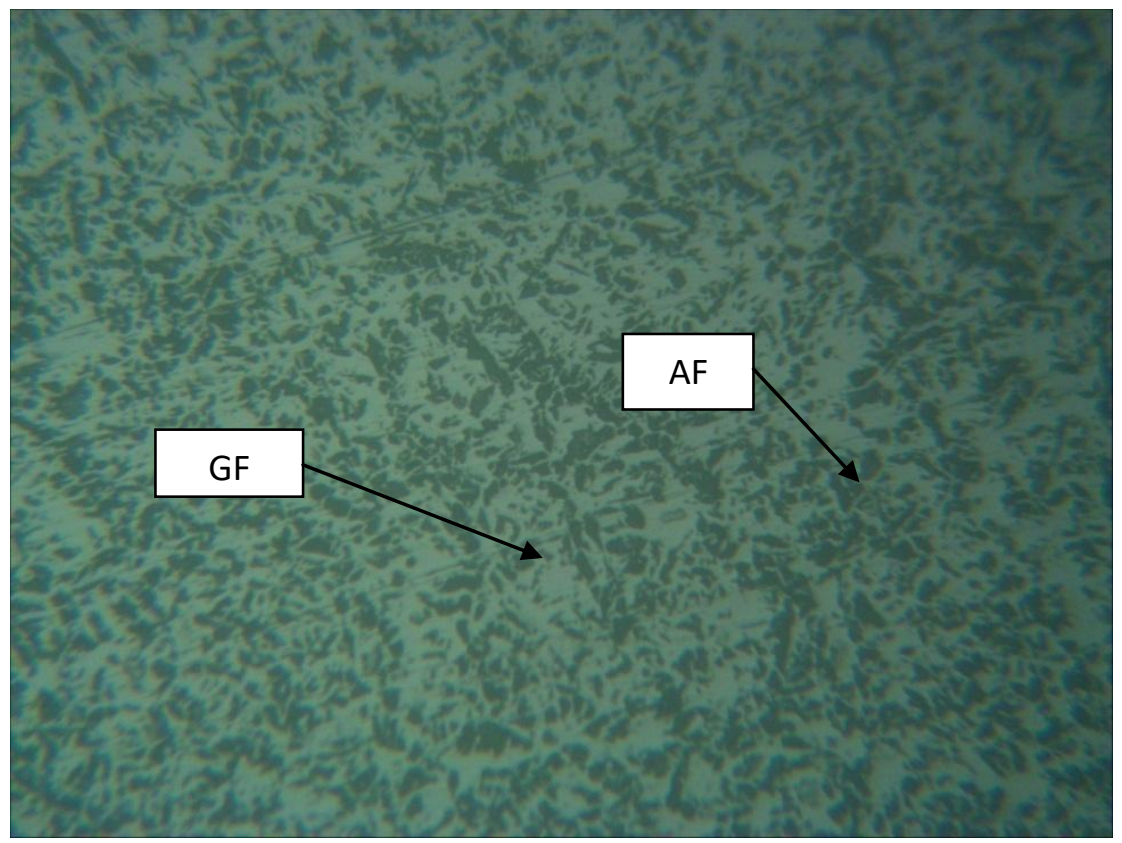

Gambar 7. Struktur Mikro Lasan Dengan Gerak Spiral Elektroda

Struktur mikro lasan dengan gerak spiral elektroda (Gambar 7) terlihat strukur mikro Grain Boundary Ferrite (GF) dan Acicular Ferrite (AF). Struktur mikro AF terlihat di seluruh area. Struktur mikro AF mendominasi seluruh area dan seragam mengunci struktur mikro GF. Struktur mikro WF pada logam lasan ini hampir tak tercipta. Struktur mikro AF pada gambar ini lebih dominan dibanding dengan struktur mikro AF pada Gambar 5 dan Gambar 6.

\subsection{Kekuatan Tarik}

Data hasil pengujian kekuatan tarik lasan SMAW pada baja ST 37 untuk tiga variasi gerak elektroda ditunjukkan dalam bentuk grafik pada Gambar 8.

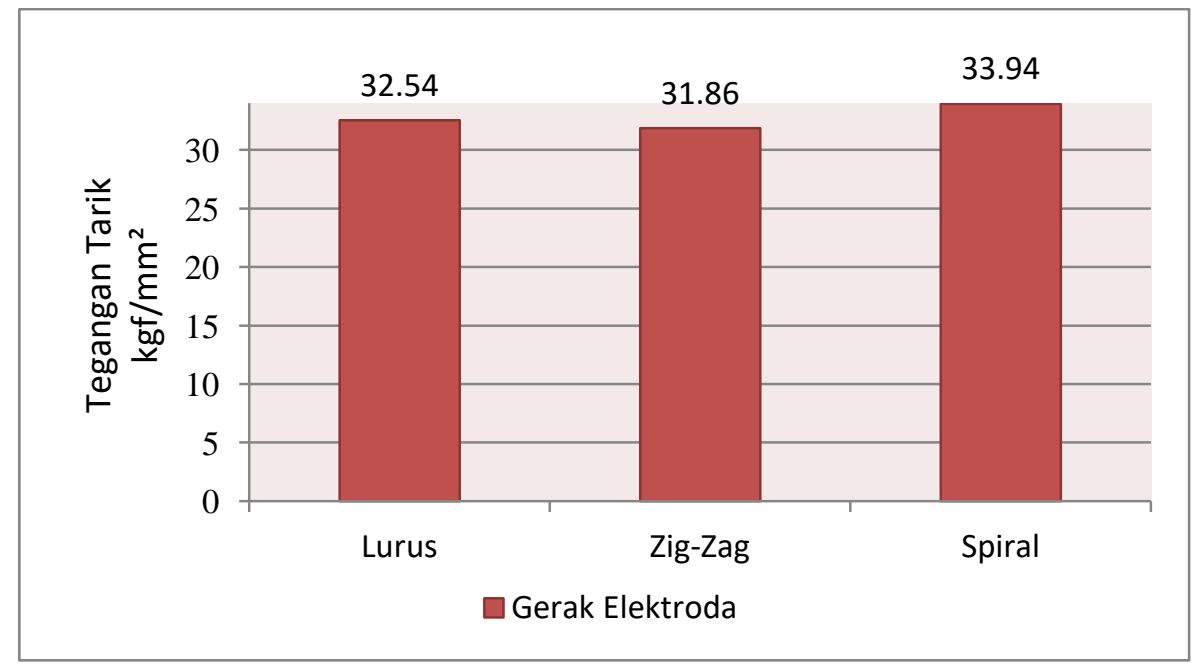

Gambar 8. Grafik Kekuatan Tarik Lasan untuk Tiga Variasi Gerak Elektroda

Tiga variasi gerak elektroda yaitu gerak lurus, zig-zag dan spiral mempengaruhi kekuatan tarik hasil lasan namun tidak signifikan. Hal ini ditunjukkan oleh nilai kekuatan tarik yang berdekatan yaitu $32,54 \mathrm{kgf} / \mathrm{mm}^{2}, 31,86 \mathrm{kgf} / \mathrm{mm}^{2}$ dan $33,94 \mathrm{kgf} / \mathrm{mm}^{2}$. Selisih nilai kekuatan tarik hanya $6,5 \%$. Namun demikian gerak elektroda spiral memberikan kekuatan 
tarik tertinggi yaitu $33,94 \mathrm{kgf} / \mathrm{mm}^{2}$. Hal ini disebabkan karena struktur mikro gerak elektroda spiral mempunyai struktur mikro AF yang lebih seragam sehingga akan mempunyai sifat ulet. Struktur ini berperan sebagai interlocking structure yang mampu menghambat laju perambatan retak. Gerakan elektroda spiral menimbulkan struktur mikro AF yang lebih merata dan seragam karena gerakan yang mengulang-ulang pada lintasan las sehingga ada penumpukan logam las dan menjadikan pendinginannya sedikit lebih lama dibandingkan dengan gerak lurus dan zig-zag. Struktur mikro AF tercipta karena pendinginan yang lambat. Selain itu, struktur mikro yang tercipta pada lasan hasil gerak lurus elektroda menunjukkan bahwa struktur GF. AF dan WF tidak beraturan sehingga keberadaan struktur mikro AF sebagai intertlocking structure tidak terlihat benar-benar mengunci struktur mikro yang lainnya.

\subsection{Tegangan Luluh}

Data hasil pengujian kekuatan luluh lasan SMAW pada baja ST 37 untuk tiga variasi gerak elektroda ditunjukkan dalam bentuk grafik pada Gambar 9

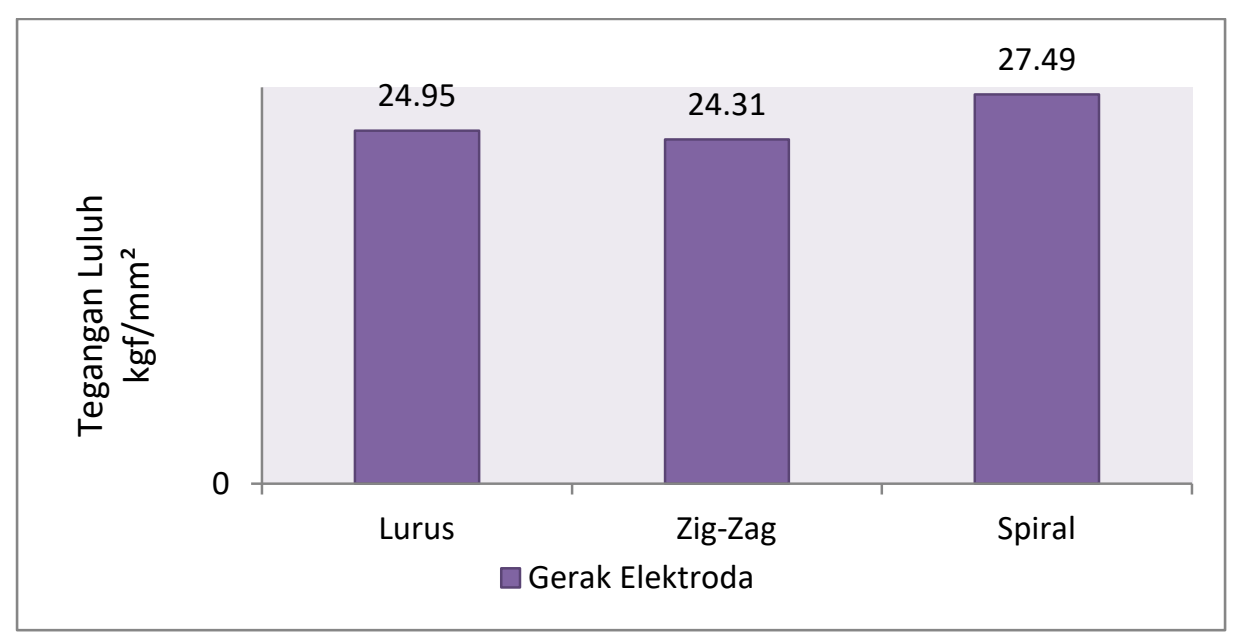

Gambar 9. Grafik Kekuatan Luluh Lasan untuk Tiga Variasi Gerak Elektroda

Gerak lurus dan zig-zag elektroda memberikan nilai tegangan luluh yang berdekatan yaitu $24,95 \mathrm{kgf} / \mathrm{mm}^{2}$ dan $24,31 \mathrm{kgf} / \mathrm{mm}^{2}$ dengan selisih nilai $2,6 \%$. Selain itu, gerak spiral elektroda memberikan nilai tegangan luluh tertinggi yaitu $27,49 \mathrm{kgf} / \mathrm{mm}^{2}$. Hal ini disebabkan karena struktur mikro gerak elektroda spiral mempunyai struktur mikro AF yang lebih seragam sehingga akan mempunyai sifat ulet. Struktur ini berperan sebagai interlocking structure yang mampu menghambat laju perambatan retak. Gerakan elektroda spiral menimbulkan struktur mikro AF yang lebih merata dan seragam karena gerakan yang mengulang-ulang pada lintasan las sehingga ada penumpukan logam las dan menjadikan pendinginannya sedikit lebih lama dibandingkan dengan gerak lurus dan zig-zag. Struktur mikro AF tercipta karena pendinginan yang lambat. 


\subsection{Cacat Las}

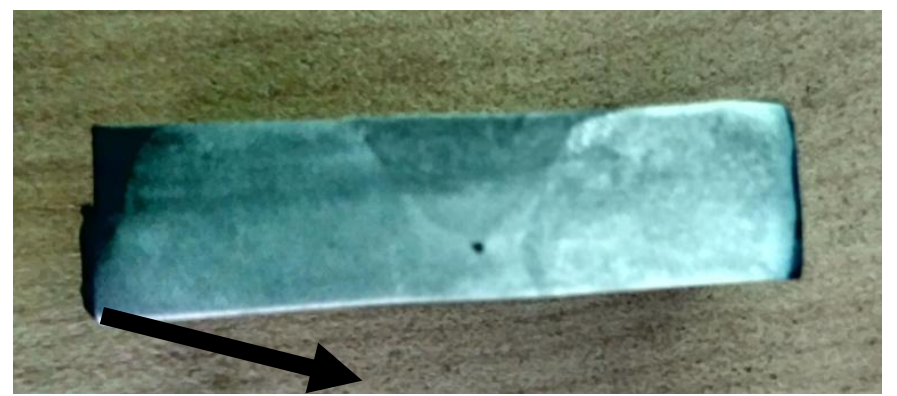

Gambar 10. Cacat Lasan Pada Gerak Lurus Elektroda

Lasan dengan gerak elektroda lurus terbentuk cacat las yaitu porositas (Gambar 10). Porositas terjadi karena adanya gas hidrogen yang tercipta akibat panas las. Panas yang mengandung gas hidrogen terperangkap di dalam logam las diakibatkan karena gerak elektroda lurus tidak dapat membuang panas pada saat proses pengelasan.
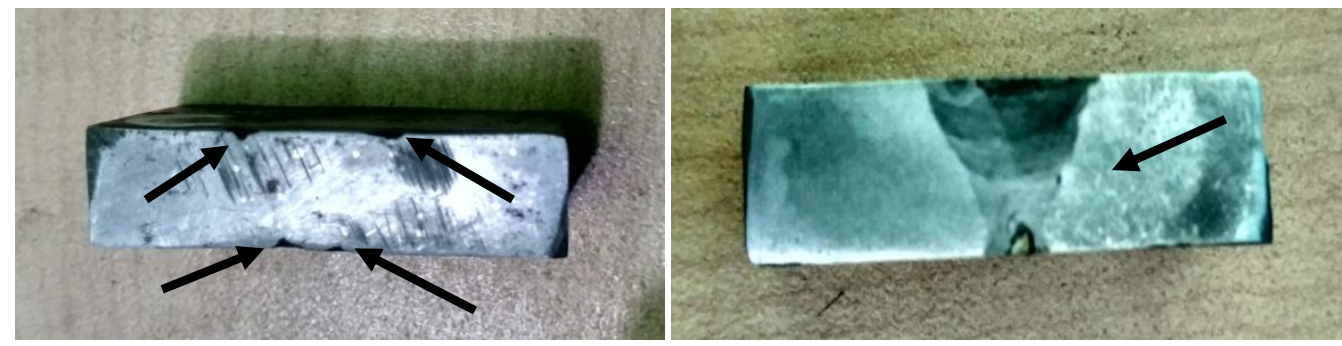

Gambar 11. Cacat Undercut dan Cacat Porositas pada Lasan dengan Gerak Zigzag Elektroda

Pada lasan dengan gerak elektroda zig-zag terbentuk cacat las yaitu porositas dan undercut. Cacat undercut terjadi pada hasil pengelasan ini karena gerak zig-zag kurang merata. Terbentuknya cacat porositas pada pengelasan root juga terjadi karena gerak elektroda zig-zag tidak dapat membuang panas pada logam las.

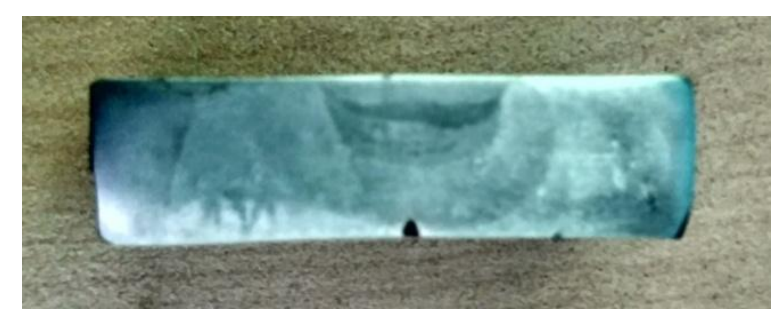

Gambar 12. Lasan dengan Gerak Spiral Elektroda

Pada lasan dengan gerak elektroda spiral tidak terbentuk cacat porositas (Gambar 12) dan tidak terbentuk cacat undercut. Tidak terjadinya cacat porositas pada gerak elektroda spiral dikarenakan gerakan tersebut memutar pada lintasan las sehinnga dapat membuang panas pada saat proses las. 


\section{Kesimpulan}

Berdasarkan hasil pengujian dan analisa data penelitian yang telah dilakukan, maka dapat ditarik kesimpulan sebagai berikut :

a. Struktur mikro Acicular Ferrite (AF) pada gerak elektroda spiral terlihat seragam, rapat dan mendominasi area. Struktur mikro AF inilah yang diharapkan dari proses pengelasan karena struktur ini sebagai interlocking structure yang mampu menghambat laju perambatan retak

b. Tiga variasi gerak elektroda yaitu gerak lurus, zig-zag dan spiral mempengaruhi kekuatan tarik hasil lasan namun tidak signifikan. Gerak elektroda spiral memberikan kekuatan tarik tertinggi yaitu $33,94 \mathrm{kgf} / \mathrm{mm}^{2}$.

c. Gerak lurus dan zig-zag elektroda memberikan nilai tegangan luluh yang berdekatan. Di sisi lain, gerak spiral elektroda memberikan nilai tegangan luluh tertinggi yaitu $27,49 \mathrm{kgf} / \mathrm{mm}^{2}$.

d. Gerak lurus dan zig-zag elektroda menghasilkan cacat las pada beberapa bagian berupa cacat porositas dan cacat undercut sedangkan gerak spiral elektroda tidak menghasilkan cacat las.

\section{Ucapan Terimakasih}

Penulis mengucapkan terima kasih kepada Pusat Penelitian dan Pengabdian pada Masyarakat (P3M) Sekolah Tinggi Teknologi Adisutjipto yang telah memberi dukungan financial pada penulisan penelitian ini.

\section{Daftar Pustaka}

[1] Arifin, A., \& Sulistyawan, T. (2017). Peningkatan Kualitas Sambungan Las Baja Karbon Rendah Dengan Metode Taguchi. FLYWHEEL: Jurnal Teknik Mesin Untirta, 2(1)

[2] Wiryosumarto, H., \& Okumura, T. (2000). Teknik pengelasan logam. Erlangga, Jakarta

[3] FAUZI BEGA PRANAWAN, D. I. T. O. (2016). Pengaruh Teknik Pengelasan Alur Spiral, Alur Zig-Zag, Dan Lurus Pada Arus 85 A Terhadap Kekuatan Tarik Baja ST 41. Jurnal Teknik Mesin, 4(02)

[4] Irwanto, A. R. (2016). Perbandingan variasi gerakan elektroda pada proses shielded metal arc welding (smaw) terhadap struktur mikro dan kekuatan bending baja Karbon rendah (Doctoral dissertation, Universitas Negeri Semarang). 